\title{
Toplu Taşımada Yatırım Kararlarının Veri Madenciliği Yöntemiyle Desteklenmesi
}

\author{
Nur Erdem ${ }^{1 *}$, Özlem Uzun Araz ${ }^{2}$ \\ ${ }^{1 *}$ Manisa Celal Bayar Üniversitesi, Mühendislik Fakültesi, Endüstri Mühendisliği Bölümü, Manisa, Türkiye, (ORCID: 0000-0002-4124-7507), \\ 191203024@ogr.cbu.edu.tr \\ ${ }^{2}$ Manisa Celal Bayar Üniversitesi, Mühendislik Fakültesi, Endüstri Mühendisliği Bölümü, Manisa, Türkiye (ORCID: 0000-0001-5630-6170), ozlem.araz@cbu.edu.tr
}

(1st International Conference on Applied Engineering and Natural Sciences ICAENS 2021, November 1-3, 2021)

(DOI: 10.31590/ejosat.1009592)

ATIF/REFERENCE: Erdem, N. \& Uzun Araz, Ö. (2021). Toplu Taşımada Yatııım Kararlarının Veri Madenciliği Yöntemiyle Desteklenmesi. Avrupa Bilim ve Teknoloji Dergisi, (28), 594-601.

$\ddot{\mathbf{O} z}$

Akıllı şehir, son zamanlarda ülkemizde ve dünyada önem kazanan bir yaklaşım olarak ön plana çıkmaktadır. Daha iyi yaşam alanları oluşturmak ve hayata değer katan şehirler inşa etmek amacıyla akıllı şehir alanındaki çalışmalar ivme kazanmıştır. Şehirlerde yapılan bu çalışmalar sayesinde sosyal yaşam için sunulan imkân ve firsatlar da gelişmektedir. Tüm insanlar bu imkân ve firsatlardan eşit derecede yararlanma hakkına sahiptir ve sosyal yapı içinde gelişerek varlıklarını sürdürebilmelidir. Engelli bireylerin, sosyal yaşamda rolünü alması, sınırlarının genişletilmesi ve yaşamlarını engelsiz sürdürebilmeleri, ulaşılabilir çevre koşullarının sağlanabileceği planlama, tasarım ve engelli bireylerin gereksinimlerinin göz önünde bulundurulduğu uygulamalar ile mümkündür. Bu çalışmada, engelli bireylerin, kamuya ait İzmir ili şehir içi toplu taşıma otobüsleri ile sağlanan ulaşım imkânlarını ve konforlarını artırmaya yönelik yapılması planlanmış teknolojik yatırımların, hangi durak lokasyonlarına ve hangi otobüs hatlarına yapılması gerektiği, akıllı şehir uygulamalarından ve veri madenciliği yönteminden faydalanılarak araştıılmıştır. Akıllı kartlardan alınan veriler, veri madenciliği yöntemleriyle analiz edilerek engelli yolcuların kullandığı otobüs hatları ve duraklar, nitelikleri önceden belirlenmiş üç ayrı sınıfa ayrılmıştır. Planlanan yatırım adetleri göz önünde bulundurularak, yatırımın yapılacağı lokasyon ve hatlar, bu sınıfların niteliklerine göre belirlenmiştir. Veri madenciliği yöntemi ve çok kriterli karar verme yöntemlerinden biri olan Analitik Hiyerarşi Prosesi (AHP) yöntemi kullanılarak oluşturulan ABC sınıflandırmasının, toplu taşıma hizmeti veren kurumun daha sonraki yatırım planlamaları ve periyodik kontrol mekanizmaları için de faydalı olacağı öngörülmektedir.

Anahtar Kelimeler: ABC sınıflandırması, AHP, Akıllı şehir, Planlama, Veri madenciliği, Yatırım.

\section{Supporting Investment Decisions in Public Transport with Data Mining Method}

\begin{abstract}
The smart city has recently come to the fore as an approach that has gained importance in our country and in the world. To create better living spaces and build cities that add value to life, studies in the field of smart cities have gained momentum. Owing to these studies carried out in cities, the opportunities and chances offered for social life are developing as well. All people have the right to benefit from these opportunities and chances equally and they should be able to develop and survive within the social structure. Disabled individuals taking their role in social life, expanding their borders and enabling them to continue their lives unhindered is possible with planning, design and practices that take into account the needs of disabled individuals, where accessible environmental conditions can be provided. In this study, the technological investments planned to be made to increase the transportation opportunities and comfort provided by public transportation buses in İzmir province to which locations and bus lines has been
\end{abstract}

* Sorumlu Yazar: 191203024@,ogr.cbu.edu.tr 
researched by using smart city applications and data mining method. Bus lines and stops used by disabled passengers have been divided into three classes with predetermined qualifications by analyzing the data taken from smart cards according to data mining methods. Considering the planned investment numbers, the locations and lines where the investment will be made are determined according to the characteristics of these classes. The ABC classification that is created by using the data mining method is expected to be useful for the public transport company's further investment planning and periodic control mechanisms.

Keywords: ABC classification, AHP, Smart city, Planning, Data mining, Investment.

\section{Giriş}

Kamu kaynaklarının etkin olarak kullanılarak, engelli bireyler gibi dezavantajlı gruplara yönelik daha fazla proje üretmeleri kamu kurumlarının en önemli sorumluluklarından biridir. Karşılaştığı engelleri aşamayan ve bu nedenlerle sosyal yaşam içinde yerini bulamayan engelli birey sayısı oldukça fazladır (Bekiroğlu 2002). Engelli bireylerin hem çalışma hayatında hem sosyal ortamlarda varlığını gösterebilmesi ve bu ortamlara erişebilirliğinin artırılması için engellilerin ulaşım imkânlarına yönelik yapılacak projeler büyük önem taşımaktadır. $\mathrm{Bu}$ projelere ayrılan kaynakların verimli kullanılması, sağlanan faydanın büyüklügünü de artıracaktır. Yapılan yatırımlar sonucunda beklenen faydanın alınabilmesi için projenin doğru yönetilmesi, analizlerin uygun yöntemlerle gerçekleştirilmesi, gerekli mühendislik uygulamalarının kullanılması oldukça önemlidir.

Günümüzde akıllı şehir uygulamalarının artmasıyla birlikte kamu sektöründe de veri toplama araçları konusunda Endüstri 4.0 teknolojilerinden faydalanılmaktadır. Kamuya ait toplu taşıma hizmeti veren firmalar, geçmişe dönük yolcu talep verilerini, geleneksel gözlem verileri yerine artık akıllı kartlardan elde etmektedirler.

Ak1ll kart teknolojilerinin benimsenmesiyle birlikte ulaşımda otomatik veri toplama sistemleri, sürekli olarak artan miktarda büyük veri tabanları oluşmasına sebep olmaktadır (Lee ve Kam 2014). Toplu taşıma planlamacılarının geleneksel yöntemlerle bu verileri yorumlaması gittikçe zorlaşmaktadır. Toplanan büyük verilerin anlamlı ve kullanılabilir hale getirilerek eyleme dönüştürülebilmesi için veri madenciliği yönteminden faydalanmak planlayıcılar ve yöneticiler için kolaylık sağlamaktadır.

Literatüre bakıldığında, birçok akıllı şehir projesinde veri madenciliği yönteminden faydalanıldığı görülmektedir. Yapılan bir çalışmada, kentsel genişlemeye etki eden faktörler, veri madenciliği yöntemi kullanılarak değerlendirilmiştir (You ve Yang 2017). Ulaşım alanında yapılan bir çalışmada, toplu taşımadaki yolcu biniş tercihleri ve yolcu sayısını tahminlemek amacıyla coğrafi ve hava durumu bilgileri kullanılarak veri madenciliği çalışması yapılmıştır (Zhang ve diğer. 2016). Yine ulaşım alanında yapılan bir çalışmada, makine öğrenimi ve veri madenciliği yöntemleri kullanılarak, sınırlı sayıdaki trafik kamerasını doğru yerlere konumlandırıp şehirdeki araç sayısını en doğru tahminleyecek model oluşturulmaya çalışılmıştır (Zhuang ve diğer. 2009). Bursa ilinde yapılan bir çalışmada, toplu taşıma kullanan öğrencilerin, toplu taşıma ile gerçekleştirdikleri hareketleri, veri madenciliği yöntemiyle analiz edilerek yeni rotalar üretilmiş ve mevcut rota ile etkinlik, verimlilik kıyaslamaları gerçekleştirilmiştir (Yılmazdamar 2019). Bir çalışmada, yeni ürün tavsiye metodolojisi geliştirmek için veri madenciliği yöntemi kullanılmıştır. Müşteriler kümeleme yöntemiyle gruplandırılmış ve AHP yöntemiyle bu kümeler önceliklendirerek veri madenciliği ve AHP yöntemi birbirini destekleyici olarak kullanılmıştır (Liu ve Shih 2005). TV üreticisi bir firmada yapılan çalışmada; firmanın müşteri tabanı, veri madenciliği yöntemi kullanılarak benzer özellikler gösteren müşteri gruplarına bölünmüştür ve bulanık AHP yöntemi ile bu grupların göreli önemleri bulunmuştur (Güçdemir 2013).

$\mathrm{Bu}$ çalışmada, İzmir ilinde büyük şehir belediyesine bağlı olarak toplu taşıma hizmeti veren ESHOT Genel Müdürlüğü'nün engelli bireylere yönelik olarak yapmayı planladığı, otobüs dış hoparlör sistemi, otobüs içi ve durak içi akıllı bilgilendirme ekranı yatırımlarının verimli kullanımının sağlanması için veri madenciliği yöntemi ile analiz çalışması gerçekleştirilmiştir. Akıllı ulaşım kartlarından alınan 2021 yılına ait Ocak-Nisan ayı verileri analiz edilerek, engelli bireyler tarafindan tercih edilen otobüs hattı ve duraklar için veri madenciliği yöntemiyle talebe yönelik ABC sınıflandırması yapılmıştır. Planlanan yatırım adetlerine bağlı olarak, belirlenen sınıfların içerisinde yer alan hat ve durakların nitelik değerlerinin büyüklüğüne göre yatırım yapılacak otobüs hattı ve durak lokasyonlarına karar verilmiştir.

\section{Materyal ve Metot}

Öncelikli olarak engelli bireylere yarar sağlamak amacıyla yapılması planlanan, akıllı şehir sistemi yatırım kararlarının destekleneceği bu çalışmada kullanılan başlıca yöntemler; veri madenciliği, Analitik Hiyerarşi Prosesi (AHP), ABC analizidir. $\mathrm{Bu}$ çalışmada Şekil 1'de gösterilen iş akışı uygulanmıştır.

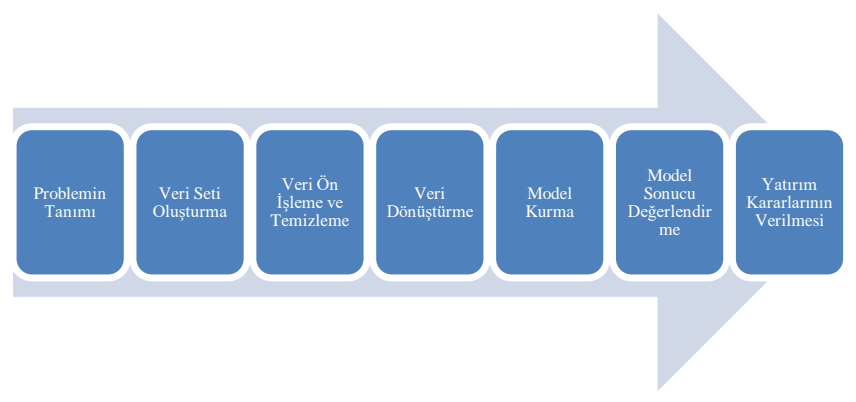

Şekil 1. Çalışmada uygulanan iş adımları

\subsection{Problemin Tanımlanması}

İzmir ilinde yaşamını sürdüren engelli bireylerin, ESHOT Genel Müdürlüğü'ne ait toplu taşıma otobüsleri ile gerçekleştirecekleri ulaşımı engelsiz hale getirmek, ulaşım konforlarını ve erişebilirlik imkânlarını artırmak amacıyla 100 adet otobüse dış hoparlör sistemi takılması ve 900 adet otobüs içerisine, hem sesli hem görsel uyarı yapan akıllı bilgilendirme ekranı takılması, ilaveten 500 adet durağa da hem sesli hem görsel uyarı yapan akıllı bilgilendirme ekranı yatırımı yapılması planlanmaktadır. Dış hoparlör sistemi öncelikli olarak görme engelli yolculara, akıllı bilgilendirme ekranı ise öncelikli olarak görme ve/ veya işitme engelli yolculara kolaylık sağlayacaktır. Yatırımların en fazla sayıda engelli yolcuya fayda 
sağlayabilmesi için belirtilen akıllı sistemlerin yerleştirileceği otobüs hattı ve durakların seçilmesi kritik önem taşımaktadır.

"Dış hoparlör sistemi" ve "akıllı bilgilendirme ekranı" yatırımlarının, hangi otobüs hattına kaç adet takılacağı ve hangi duraklara yerleştirileceği sorularının yanıtlanması için akıllı yolcu kartlarından alınan verilerin bulunduğu veri tabanı kullanılarak, veri madenciliği yönteminin kullanılması uygun bulunmuştur.

\subsection{Veri Seti Oluşturma}

Bu çalışmada kullanılan veri seti, ESHOT Genel Müdürlüğü tarafindan depolanan yolcu veri tabanından temin edilmiştir. Veriler, yolcuların toplu taşıma araçlarına binerken kullandığ akıllı kartlardan elde edilmektedir. Çalışmadaki hesaplamalarda, 2021 Ocak-Nisan ayları arasındaki engelli yolcu biniş verileri kullanılmıştır. Büyük veri tabanı içerisinden; 5.116.670 örnek ve 5 öznitelik seçilmiştir. Seçilen öznitelikler ve açıklamaları aşağıdaki Tablo 1'de görülmektedir.

Tablo 1. Veri setinden elde edilen öznitelikler ve açıklaması

\begin{tabular}{l|c}
\hline Öznitelik & Açıklaması \\
\hline Mifareid & Kullanıcı kartına ait kart numarası \\
\hline Engel Türü & $\begin{array}{c}\text { Engelli bireyin hangi engele sahip } \\
\text { olduğu bilgisi }\end{array}$ \\
\hline Gün & $\begin{array}{c}\text { Yolculuğun yapıldığı gün/ay/yıl } \\
\text { bilgisi }\end{array}$ \\
\hline Hat No & $\begin{array}{c}\text { Engelli yolcunun biniş yaptığı toplu } \\
\text { taşıma aracı numarası }\end{array}$ \\
\hline Durak ID & $\begin{array}{c}\text { Engelli yolcunun toplu taşıma aracına } \\
\text { biniş yaptığı durağın numarası }\end{array}$ \\
\hline
\end{tabular}

\subsection{Veri Ön İşleme ve Temizleme}

Veri temizleme; eksik verileri düzenleme, gürültülü veya sapan verileri, çalışma için anlam ifade etmeyen verileri uzaklaştırma işlemidir. Bilgi keşfinin bu basamağı veri setinin güvenilirliğini artırır (Gemici 2012).

Veri ön işleme ve temizleme adımında; özniteliklerin her biri değerlendirilerek aykırı ve eksik veriler tespit edilmiştir. "Gün", "hat no", "durak id" bilgisi bulunmayan "mifareid" kayıtları elenmiştir, engel türü bilgisi bulunmayan kayıtlar ise "genel engel türü” olarak tamamlanmıştır.

Akıllı yolcu kartlarından alınan veriler tüm toplu taşıma araçlarına binişleri kapsamaktadır. Otobüs harici binişler veri setinden ayıklanmıştır. Toplam 1.383.828 satır veri silinmiştir. Geriye kalan 3.732.842 veriyle çalışmaya devam edilmiştir.

\subsection{Veri Dönüştürme}

Veri dönüştürme; hazır ve gelişmiş veri madenciliği için daha iyi veri üretmek amacıyla uygulanır ve bu adım bütün veri keşif süreci için çok kritiktir (Akpınar 2000).

Veri dönüş̧ürme adımında; veri setinde bulunan öznitelikler modelde kullanmak için anlamlı hale getirilmiştir. Gün/ay/yıl olarak belirtilmiş olan binişin yapıldığı tarih bilgisi, gün bazına indirgenmiştir. Örneğin: 12/03/2021 verisi Cuma gününe denk geldiği için "Gün” özniteliğinin bulunduğu hücre değeri, "Cuma" olarak değiştirilmiştir. Bu dönüşüm sayesinde, engelli yolcu biniş taleplerinin gün bazında değerlendirilmesine imkân sağlanmıştır.
Engelli yolcu biniş verilerinin haftanın 7 günü bazında ayrı ayrı analiz edilmesi, haftanın farklı günlerinde lokasyonlara olan gidiş talep değişkenliklerinin analiz edilmesini mümkün kılar. $\mathrm{Bu}$ sebeple; veri analizi sonuç değerlendirme aşamasında ayırt edilebilirliğin sağlanması için "Hat No" verisi gün bilgisiyle birleştirilmiştir. Örneğin, Pazartesi günü "Hat No" 100 olan bir biniş kaydında artık "Hat No" hücresinde "100d1" görülmektedir. "d1", Pazartesi gününü temsil eden metin ifadesidir. Haftanın diğer günleri için; Salı "d2", Çarşamba "d3", Perşembe “d4", Cuma “ d5", Cumartesi “d6", Pazar "d7” ile ifade edilmektedir.

Yatırım kararlarının verilmesinde "engel türü” bilgisi ve o engel türüne ait yolcuların tercih ettiği otobüs hatları kritik önem taşımaktadır. Bu sebeple, otobüslere yapılacak yatırımların karar çalışması için; sütunda hat numaraları, satırlarda engel türü bilgisi olacak şekilde otobüs hatlarına günlük biniş sayılarının bulunduğu matris hazırlanmıştır. Otobüs duraklarına yapılacak yatırım lokasyonları kararı için ise satır kısmında engel türü sütun kısmında "Durak id" özniteliği olacak şekilde duraklardan biniş adetlerinin bulunduğu matris oluşturulmuştur. Sütundaki hat numarası ya da durak id ye karşılık gelen engelli biniş sayıları, 2021 Ocak-Nisan ayları arasındaki 4 aylık toplam biniş sayısını ifade etmektedir.

Otobüslerin üzerindeki hat numaralarının günlük olarak değiştirilmesi mümkündür. $\mathrm{Bu}$ sebeple otobüs hatlarına olan talep gün bazında değerlendirilerek talep değişkenliği analiz edilmiştir. Dış hoparlör sistemi yatırımında gün bazlı değerlendirmenin yapıldığı bir model kurulurken, akıllı bilgilendirme ekranı yatırımları için gün bazlı değerlendirmeye gerek duyulmamıştır.

Pazartesi gününe ait hazırlanmış, otobüs araçlarına özel veri tablosundan bir örnek alan Tablo 2'de görülmektedir.

Tablo 2. Otobüs yatırımları için dönüş̧ürülmüş veri matrisi

\begin{tabular}{l|c|c|c|c|c}
\hline Gün & $\begin{array}{c}\text { Çoklu } \\
\text { Engel }\end{array}$ & $\begin{array}{c}\text { Dil ve } \\
\text { Konuş } \\
\text { ma } \\
\text { Engeli }\end{array}$ & $\begin{array}{c}\text { Görme } \\
\text { Engeli }\end{array}$ & $\begin{array}{c}\text { İşitme } \\
\text { Engeli }\end{array}$ & $\begin{array}{c}\text { Toplam } \\
\text { (Tüm } \\
\text { Engel } \\
\text { Türleri } \\
\text { Dahil) }\end{array}$ \\
\hline $102 d 1$ & 327 & 2 & 30 & 27 & 969 \\
\hline $104 d 1$ & 906 & 23 & 128 & 143 & 3404 \\
\hline $105 d 1$ & 953 & 34 & 231 & 146 & 3481 \\
\hline $108 d 1$ & 382 & 3 & 63 & 69 & 1375 \\
\hline $10 d 1$ & 291 & 2 & 64 & 22 & 1495 \\
\hline $111 d 1$ & 633 & 6 & 136 & 105 & 2885 \\
\hline
\end{tabular}

Duraklara yerleştirilecek akıllı bilgilendirme ekranı yatırımına özel oluşturulmuş veri tablosundan bir örnek alan Tablo 3'te görülmektedir.

Tablo 3. Durak yatırımları için dönüştürülmüş veri matrisi

\begin{tabular}{l|c|c|c|c|c}
\hline $\begin{array}{l}\text { Durak } \\
\text { ID }\end{array}$ & $\begin{array}{c}\text { Çoklu } \\
\text { Engel }\end{array}$ & $\begin{array}{c}\text { Dil ve } \\
\text { Konuşma } \\
\text { Engeli }\end{array}$ & $\begin{array}{c}\text { Görme } \\
\text { Engeli }\end{array}$ & $\begin{array}{c}\text { İşitme } \\
\text { Engeli }\end{array}$ & $\begin{array}{c}\text { Kronik } \\
\text { Rahatsız } \\
\text { lık }\end{array}$ \\
\hline 10005 & 273 & 6 & 35 & 37 & 313 \\
\hline 10007 & 1583 & 10 & 181 & 341 & 1462 \\
\hline 10008 & 1081 & 15 & 163 & 112 & 829 \\
\hline 10009 & 909 & 10 & 162 & 145 & 795 \\
\hline 10010 & 537 & 17 & 108 & 85 & 438 \\
\hline \multicolumn{7}{|r|}{}
\end{tabular}




\subsection{Model Kurma}

Model kurma adımında; veri madenciliği analiz programında çözümlenecek model kurulmuş ve çözüm algoritması seçilmiştir.

\subsubsection{Modelin Kurulmast}

D1ş hoparlör sisteminin kurulacağı otobüs hatlarının belirlenmesi, akıllı bilgilendirme ekranının yerleştirileceği otobüs hatlarının belirlenmesi, akıllı bilgilendirme ekranlarının yerleştirileceği durak lokasyonlarının belirlenmesi kararları için 3 ayrı model oluşturulmuştur:

Model 1: Diş hoparlör sisteminin kurulacağı otobüs hatlarının belirlenmesi

Model 2: Akıllı bilgilendirme ekranının yerleştirileceği otobüs hatlarının belirlenmesi

Model 3: Akıllı bilgilendirme ekranlarının yerleştirileceği durak lokasyonlarının belirlenmesi

Her modele özel nitelikler belirlenmiştir. Belirlenen nitelikler, kullanıldığ 1 model ve açıklamaları Tablo 4'te görülmektedir.

Tablo 4. Modellerde kullanılan nitelikler ve açıklamaları

\begin{tabular}{|c|c|c|}
\hline Nitelik & Açıklama & $\begin{array}{c}\text { Kullanıldığ } \\
\text { Model }\end{array}$ \\
\hline $\begin{array}{l}\text { Görme Engelli } \\
\text { Talebi }\end{array}$ & $\begin{array}{l}\text { Belirtilen günde } \\
\text { yolculuk yapan görme } \\
\text { engelli bireylerin } \\
\text { belirtilen hattı tercih } \\
\text { etme oranıdır. }\end{array}$ & Model 1 \\
\hline $\begin{array}{l}\text { Görme ve } \\
\text { Işitme Engelli } \\
\text { Talebi }\end{array}$ & $\begin{array}{l}\text { Belirtilen günde } \\
\text { yolculuk yapan görme } \\
\text { ve işitme engelli } \\
\text { bireylerin belirtilen } \\
\text { hattı/ durağ1 tercih } \\
\text { etme oranıdır. }\end{array}$ & $\begin{array}{l}\text { Model } 2 \\
\text { Model } 3\end{array}$ \\
\hline $\begin{array}{l}\text { Tüm Engelli } \\
\text { Talebi }\end{array}$ & $\begin{array}{c}\text { Belirtilen günde } \\
\text { yolculuk yapan engelli } \\
\text { bireylerin belirtilen } \\
\text { hattı/ durağ1 tercih } \\
\text { etme oranıdır. }\end{array}$ & $\begin{array}{l}\text { Model } 1 \\
\text { Model } 2 \\
\text { Model } 3\end{array}$ \\
\hline $\begin{array}{l}\text { Tüm Yolcu } \\
\text { Talebi }\end{array}$ & $\begin{array}{c}\text { Belirtilen otobüs } \\
\text { hattının belirtilen } \\
\text { gündeki sefer sayısıdır. }\end{array}$ & $\begin{array}{l}\text { Model } 1 \\
\text { Model } 2\end{array}$ \\
\hline
\end{tabular}

Nitelikler belirlenirken yapılacak yatırımdan etkilenecek yolcu sınıfları dikkate alınmıştır. Engelsiz bireylerin biniş kayıtları gizli veri niteliğinde olmasından dolayı, biniş adetleriyle orantılı olduğu belirtilen, otobüs hattı günlük sefer sayıları kullanılmıştır.

Nitelikler ve nitelik değerlerinin belirlenmesinin ardından verilerin normalizasyonu gerçekleştirilmişstir.

Model 1'e ait normalize edilmiş veri tablosundan bir örnek alan Tablo 5'te görülmektedir.
Tablo 5. Model 1 normalize edilmiş veri tablosu

\begin{tabular}{c|c|c|c}
\hline Hat No & $\begin{array}{c}\text { Görme } \\
\text { Engelli Talebi }\end{array}$ & $\begin{array}{c}\text { Tüm Engelli } \\
\text { Talebi }\end{array}$ & $\begin{array}{c}\text { Tüm Yolcu } \\
\text { Talebi }\end{array}$ \\
\hline $23 d 1$ & 0,7041 & 0,7649 & 0,7356 \\
\hline $18 d 1$ & 0,7435 & 0,7456 & 0,5862 \\
\hline $42 d 1$ & 0,5943 & 0,5951 & 0,8276 \\
\hline $46 d 1$ & 0,6091 & 0,5543 & 0,8314 \\
\hline $550 d 1$ & 0,6905 & 0,5165 & 0,7739 \\
\hline
\end{tabular}

\subsection{2. Çözüm Algoritmasının Belirlenmesi}

Yatırım yapılacak sistemlerin atanacağı otobüs hattı ve durakların belirlenmesi için hazırlanan veri setinin k-means algoritması kullanılarak çözümlenmesi ve 3 sınıfa ayrılmasına karar verilmiştir.

K-means yöntemi, en yaygın kullanılan gözetimsiz öğrenme yöntemlerinden biridir. K-means'in atama mekanizması, her verinin sadece bir kümeye ait olabilmesine izin verir (Evans ve diğer. 2005). K-means algoritmasının genel mantığı $\mathrm{n}$ adet veri nesnesinden oluşan bir veri kümesini, giriş parametresi olarak verilen $\mathrm{k}$ adet kümeye bölümlemektir. Amaç, gerçekleştirilen bölümleme işlemi sonunda elde edilen kümelerin, küme içi benzerliklerinin maksimum ve kümeler arası benzerliklerinin minimum olmasını sağlamaktır. Çalışmada; tıp alanında yapılan bir veri madenciliği uygulamasında kullanılmış olan, (1) numaralı Öklit uzaklığı formülü temel alınarak kümeleme yapılmaktadır (Dinçer 2006).

$$
\mathrm{p}=(\mathrm{p} 1, \mathrm{p} 2, \ldots, \mathrm{pn}) \text { ve } \mathrm{q}=(\mathrm{q} 1, \mathrm{q} 2, \ldots, \mathrm{qn}) \text { olmak üzere; }
$$

$\sqrt{\sum_{i=1}^{n}\left(p_{i}-q_{i}\right)^{2}}=\sqrt{\left(p_{1}-q_{1}\right)^{2}+\left(p_{2}-q_{2}\right)^{2}+\cdots+\left(p_{n}-q_{n}\right)^{2}}$

Veri setinde bulunan nesneler 3 kümeye ayrıldıktan sonra AHP yöntemi ile sınıfların ağırlık değerleri hesaplanarak en yüksek ağırlık değerine sahip olan kümenin A sınıfı, sonra B ve en düşük ağırlık değerine sahip olan kümenin ise $C$ sınıfı olarak adlandırılmasına karar verilmiştir. Otobüs hatları ve duraklar için $\mathrm{ABC}$ analizinin yapılması, toplu taşıma hizmeti veren kuruma daha sonraki yatırım kararlarında, planlama ve denetim konularında da fayda sağlayacağı düşünülmüştür.

ABC Analizi, pareto ilkesine dayanır ve hem nicel hem nitel sınıflandırmaya imkân tanır. ABC analizi, sınıflandırılacak nesneleri 3 alt gruba ayırmaktadır. A Grubu'na ait olanlar organizasyon için önemli unsurlardır. B Grubu'na ait olanlar orta düzeyde bir öneme sahiptir. C Grubu'nda bulunanlar ise organizasyon için en az öneme sahip olanlardır (Kıyak ve diğer. 2016). Genellikle en önemli grup, pareto ilkesi olarak nesnelerin \%20'sinde bulunur. Şekil 2'de görülen grafikle pareto ilkesinin nesneler üzerindeki zihniyeti gösterilmiştir (Chen 2012).

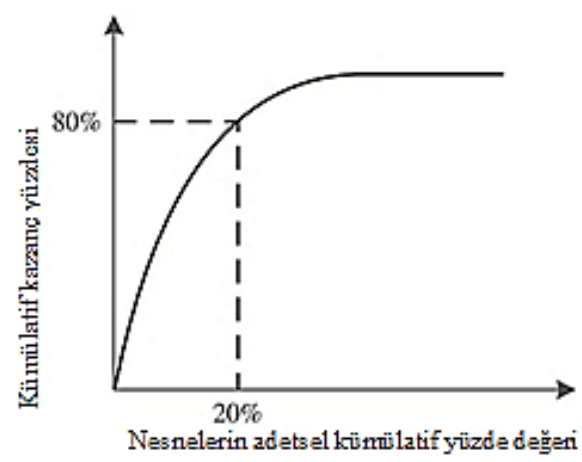

Şekil 2. ABC analizi pareto ilkesi 
Örnek olarak, duraklar için oluşturulmuş A-B-C sınıflarının nitelikleri Tablo 6'da görülmektedir.

Tablo 6. A-B-C sinıflarina ait nitelikler

\begin{tabular}{|c|c|c|}
\hline Sinıf & Özellikler & $\begin{array}{c}\text { Durak Planlama/Yönetim } \\
\text { Politikası }\end{array}$ \\
\hline$A$ & $\begin{array}{c}\text { Görme ve işitme } \\
\text { engelliler yüksek } \\
\text { s1klıkta } \\
\text { kullanıyor. } \\
\text { Engelli bireyler } \\
\text { s1klıkla } \\
\text { kullanıyor. }\end{array}$ & $\begin{array}{c}\text { Otobüs durak atamaları } \\
\text { yüksek sıklıkla kontrol } \\
\text { edilmeli. } \\
\text { Duraklardan geçen otobüs } \\
\text { hatlarının günlük sefer } \\
\text { sayısı uygunluk kontrolü } \\
\text { yüksek sıklıkta yapılmalı. } \\
\text { Duraklardan geçen otobüs } \\
\text { hatlarının plana uyum oranı } \\
\text { yüksek tutulmalı. } \\
\text { Engelli bireylere fayda } \\
\text { sağlayabilecek yatırımlarda } \\
\text { yüksek öncelik verilmeli. }\end{array}$ \\
\hline$B$ & $\begin{array}{c}\text { Görme ve işitme } \\
\text { engelliler sıklıkta } \\
\text { kullanıyor. } \\
\text { Engelli bireyler } \\
\text { orta sıklıkta } \\
\text { kullanıyor. }\end{array}$ & $\begin{array}{l}\text { Otobüs durak atamaları orta } \\
\text { sıklıkla kontrol edilmeli. } \\
\text { Duraklardan geçen otobüs } \\
\text { hatlarının günlük sefer } \\
\text { sayısı uygunluk kontrolü } \\
\text { orta sıklıkta yapılmalı. } \\
\text { Engelli bireylere fayda } \\
\text { sağlayabilecek yatırımlarda } \\
\text { orta öncelik verilmeli. }\end{array}$ \\
\hline$C$ & $\begin{array}{c}\text { Görme ve işitme } \\
\text { engelliler orta ve } \\
\text { düşük sıklıkta } \\
\text { kullanıyor. } \\
\text { Engelli bireyler } \\
\text { düşük sıklıkla } \\
\text { kullanıyor. }\end{array}$ & $\begin{array}{l}\text { Otobüs durak atamaları } \\
\text { düşük sıklıkla kontrol } \\
\text { edilebilir. } \\
\text { Duraklardan geçen otobüs } \\
\text { hatlarının günlük sefer } \\
\text { sayısı uygunluk kontrolü } \\
\text { düşük sıklıkta yapılabilir. } \\
\text { Engelli bireylere fayda } \\
\text { sağlayabilecek yatırımlarda } \\
\text { düşük öncelik verilmelidir. }\end{array}$ \\
\hline
\end{tabular}

\subsection{Model Sonrası Değerlendirme}

Excel tabanlı Xlstat veri madenciliği programı kullanılarak model çözümlenmiştir. Model 1, Model 2 ve Model 3 'te yer alan nesneler 3 kümeye ayrılmıştır.

\subsubsection{Model Performans Değerlendirmesi}

K-means algoritmasının doğruluk ve performansı, büyük ölçüde ilk küme merkezlerine bağlıdır. K-means kümeleme algoritmasının ana amacı, küme içi varyasyon (SSW) değerinin minimizasyonu, kümeler arası varyasyon (SSB) değerinin maksimize edilmesidir (Gupta ve Chandra 2019). SSW değerinin SSB değerinden küçük olması kümeleme algoritmasının doğru çalıştığını gösteren önemli bir ölçüttür. Çalıştırılan modellerin tümünde, küme içi varyasyon değerinin, kümeler arası varyasyon değerinden küçük olmasından dolayı modelleme sonucu başarılı olarak değerlendirilmiştir. Model1 Pazartesi gününe ait çalıştırılan algoritmanın, Model 2 ve Model 3 algoritmalarının sonuç raporunda görülen SSW ve SSB değerleri Tablo 7'de görülmektedir.

e-ISSN: 2148-2683
Tablo 7. Modellerin SSW-SSB değerleri

\begin{tabular}{l|c|c}
\hline Model No & SSW & SSB \\
\hline Model 1 (Pazartesi) & $\% 21,40$ & $\% 78,60$ \\
\hline Model 2 & $\% 21,15$ & $\% 78,85$ \\
\hline Model 3 & $\% 23,43$ & $\% 76,57$ \\
\hline
\end{tabular}

\subsubsection{ABC Sinıflarının Belirlenmesi}

Model 1, Model 2 ve Model 3 veri setindeki nesneler kmeans algoritması ile 3 kümeye ayrılmıştır ancak belirlenen kümelerin hangisinin daha öncelikli olduğu bilgisi k-means algoritması ile belirlenememektedir. Kümelerin birbirine göre önceliğinin belirlenmesi için Analitik Hiyerarşi Prosesi (AHP) yöntemine başvurulmuştur. AHP yöntemi; birden çok kriteri göz önüne alarak ve bu kriterlere önem veya üstünlük tanımlayarak çeşitli alternatifler arasından seçim yapmayı sağlayan birçok kriterli karar verme yöntemidir(Gülenç ve Bilgin 2010). AHP yönteminin amac1, verilen alternatifler için onlarla bağlantılı önceliklerin bir skalaya konularak, karar vericinin sezgisel yargılarını ve alternatiflere ait karşılaştırma tutarlılığını da dikkate alarak, bu sürecin en etkin şekilde tamamlanmasını sağlamaktır (Özyörük 2008). AHP'nin 4 aşamalı genel hiyerarşik yapısı Şekil 3'te görülmektedir.

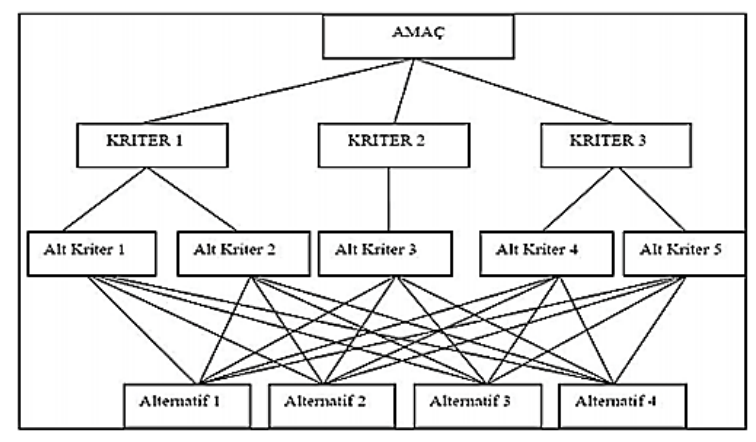

Şekil 3. Genel hiyerarşi yapısı

Modelde kullanılan nitelikler; Tablo 8'de görülen AHP Standart Önem Skalasına göre derecelendirilerek niteliklerin ağırlık değerleri belirlenmiştir (Saaty 2008). Model 1'e ait nitelikler için oluşturulan karşılaştırma matrisi ve hesaplanan ağırlık değerleri Tablo 9'da görülmektedir.

Tablo 8. Standart tercih tablosu

\begin{tabular}{l|l}
\hline Önem Değerleri & Değer Tanımları \\
\hline 1 & Eşit Önemde \\
\hline 3 & Biraz Daha Önemli (Az Üstünlük) \\
\hline 5 & Oldukça Önemli (Fazla Üstünlük) \\
\hline 7 & Çok Önemli (Çok Üstünlük) \\
\hline 9 & $\begin{array}{l}\text { Son Derece Önemli (Kesin } \\
\text { Üstünlük) }\end{array}$ \\
\hline $2,4,6$ ve 8 & Ara Değerler (Uzlaşma Değerleri) \\
\hline
\end{tabular}

Tablo 9. Nitelik karşılaştırma matrisi ve ă̆ırlık dĕgerleri

\begin{tabular}{l|c|c|c|c}
\hline Nitelik & $\begin{array}{c}\text { N1 } \\
\text { (Görme } \\
\text { Engelli } \\
\text { Talebi) }\end{array}$ & $\begin{array}{c}\text { N2 (Tüm } \\
\text { Engelli } \\
\text { Talebi) }\end{array}$ & $\begin{array}{c}\text { N3 (Tüm } \\
\text { Yolcu } \\
\text { Talebi) }\end{array}$ & $\begin{array}{c}\text { Ağırlık } \\
\text { Değeri }\end{array}$ \\
\hline$N 1$ & 1 & 3 & 5 & 0,63 \\
\hline$N 2$ & 0,33 & 1 & 3 & 0,26 \\
\hline$N 3$ & 0,20 & 0,33 & 1 & 0,11 \\
\hline \multicolumn{5}{|r}{}
\end{tabular}


Modelin k-means algoritmasıyla çözümlenmesi sonucu alınan rapordan elde edilen kümelerin "küme merkezi (class centroid)" değerleri, niteliklerin ağırlık değerleri ile çarpılarak kümelerin ağırlıklı toplamları hesaplanmış ve en yüksek değere sahip küme A sınıfı, ikinci yüksek değere sahip küme B sınıfı, diğer küme ise $\mathrm{C}$ sınıfı olarak belirlenmiştir. Model 1, Pazartesi günü için uygulanmış örnek $\mathrm{ABC}$ sınıflandırma hesaplaması Tablo 10'da görülmektedir.

Tablo 10. Kümeler arasında ABC sınıflandırması

\begin{tabular}{l|c|c|c|c|c}
\hline Küme & $\begin{array}{c}\text { Görme } \\
\text { engelli } \\
\text { talebi }\end{array}$ & $\begin{array}{c}\text { Tüm } \\
\text { engelli } \\
\text { talebi }\end{array}$ & $\begin{array}{c}\text { Tüm } \\
\text { yolcu } \\
\text { talebi }\end{array}$ & Ăğırlık & Sınıf \\
\hline 1 & 0,416 & 0,428 & 0,625 & 0,147 & $\mathrm{~A}$ \\
\hline 2 & 0,121 & 0,149 & 0,354 & 0,051 & $\mathrm{~B}$ \\
\hline 3 & 0,022 & 0,030 & 0,100 & 0,011 & $\mathrm{C}$ \\
\hline
\end{tabular}

Benzer hesaplama tüm modeller için uygulanmış ve kümelere A-B-C sınıflandırması yapılmıştır.

\subsubsection{Günlere Göre Model Sonucunun Karşılaştırması}

Model 1'de haftanın 7 günü için 7 ayrı veri seti modeli çalıştırılmıştır. Haftanın her bir günü için ABC sınıflandırması yapılmış ve her güne ait sınıfların içerisine atanmış olan hatlar birbiriyle karşılaştırılmıştır. Talebin en yüksek olduğu ve yatırımın büyük kısmını karşılayacak A sınıfına ait karşılaştırma Tablo 11'de görülmektedir. En yüksek hat sayısına sahip Cuma gününe atanmış 52 hattın diğer günlerdeki hat numaralarını barındırma oranı hesaplanarak uyum oranına ulaşılmıştır.
Tablo 11. Günler arasında A sınıfina seçilen hatların benzerlik oranl

\begin{tabular}{l|c|c}
\hline Gün & A Sinıfı Hat Sayısı & Uyum Oranı \\
\hline Pazartesi & 51 & $100 \%$ \\
\hline Salı & 47 & $100 \%$ \\
\hline Çarşamba & 49 & $100 \%$ \\
\hline Perşembe & 47 & $100 \%$ \\
\hline Cuma & 52 & $100 \%$ \\
\hline Cumartesi & 46 & $98 \%$ \\
\hline Pazar & 34 & $82 \%$ \\
\hline
\end{tabular}

Tablo 11'de görüldüğü üzere hafta içi günleri arasındaki uyum $\% 100$ ve hat sayıları birbirine oldukça yakın bulunurken hafta sonu günlerinde (Cumartesi, Pazar) farklılık görülmektedir. Bu sebeple Model 1'de çözümlenen dış hoparlör sistemi yatırımı için; taşıma hizmeti veren kuruma planlamada iş yükü getirmemesi amaciyla, hafta içi günlerinin atama adetlerinin ortalaması alınarak, her gün için hoparlör sistemi yatırım kararlarının ortaklaştırılması uygun bulunmuştur.

\subsection{Yatırım Kararlarının Verilmesi}

Yatırım adetlerinin ABC sınıfları içerisindeki otobüs ve duraklara atanması işlemi için Şekil 4'te görülen algoritma oluşturulmuştur.

Otobüs hat numaralarına ait günlük araç sayısı verileri veri setine eklenerek, Model 1 ve Model 2 için kümelerin içerisinde yer alan nesne sayısı güncellenmiştir. Örneğin: Tablo 12'de görüldüğü üzere, A sınıfında yer almakta olan 680 numaralı hatta ait toplam 26 adet toplu taşıma aracı bulunmaktadır.

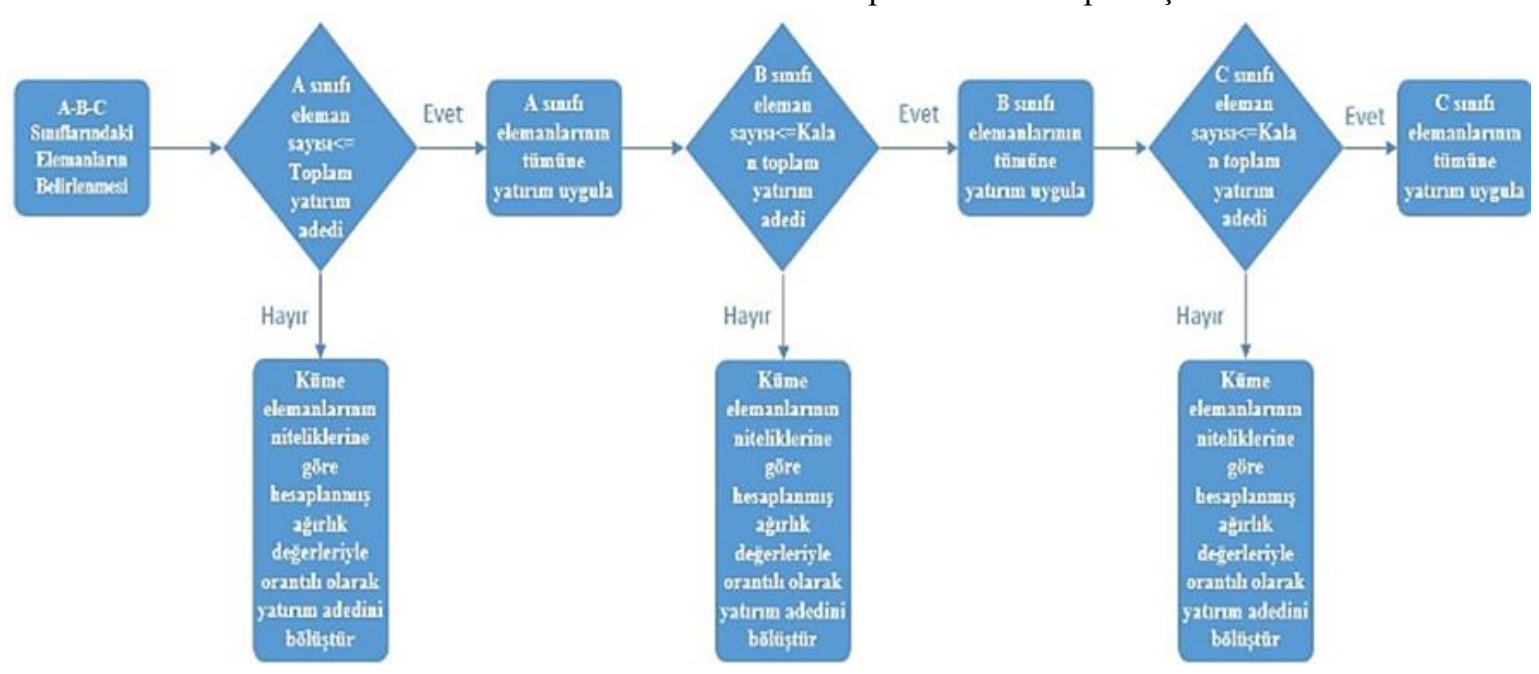

Şekil 4. Yatırım atama algoritması

Tablo 12. Sefere çıkan günlük araç adedi verisi

\begin{tabular}{l|c|c}
\hline Sınıf & Hat No & $\begin{array}{c}\text { Otobüs Hattı Sefere } \\
\text { Çıkan Araç Sayısı }\end{array}$ \\
\hline$A$ & 680 & 26 \\
\hline$A$ & 23 & 12 \\
\hline$A$ & 42 & 14 \\
\hline
\end{tabular}

Model 1, Model 2, Model 3 için ABC sınıflarında bulunan nesnelerin toplam adetleri Tablo 13'te görülmektedir. Model 1 için hafta içi günlerinin ortalama değeri belirtilmiştir.
Tablo 13. A-B-C sınıflarındaki hat, araç ve durak adetleri

\begin{tabular}{l|c|c|c|c|c}
\hline Sınıf & $\begin{array}{c}\text { Model 1 } \\
\text { Toplam } \\
\text { Hat } \\
\text { Adedi }\end{array}$ & $\begin{array}{c}\text { Model 1 } \\
\text { Toplam } \\
\text { Araç } \\
\text { Sayısı }\end{array}$ & $\begin{array}{c}\text { Model 2 } \\
\text { Toplam } \\
\text { Hat } \\
\text { Adedi }\end{array}$ & $\begin{array}{c}\text { Model 2 } \\
\text { Toplam } \\
\text { Araç } \\
\text { Sayısı }\end{array}$ & $\begin{array}{c}\text { Model 3 } \\
\text { Toplam } \\
\text { Durak } \\
\text { Adedi }\end{array}$ \\
\hline$A$ & 49 & 634 & 58 & 685 & 32 \\
\hline$B$ & 101 & 614 & 119 & 651 & 301 \\
\hline$C$ & 178 & 358 & 153 & 274 & 6549 \\
\hline
\end{tabular}

Model 1 ve Model 2 kümeleri için toplam araç sayılarının belirlenmesinin ardından Şekil 4'teki algoritma adımları 599 
izlenerek, taşıma hizmeti sağlayan kurumun belirttiği yatırım adetlerine göre yatırımın yapılacağı otobüs hattı numaraları ve durak lokasyonları belirlenmiştir. Şekil 4'teki algoritma adımlarının açıklaması aşağıda belirtilmiştir:

Adım 1: A sinifinda bulunan toplam otobüs ya da durak sayısının toplam yatırım adedinden büyük olması durumunda küme içerisindeki elemanların niteliklere göre ağırlık değerleri hesaplanır ve ağırlık değeri yüksek olan hat numaralarına ya da duraklara öncelik verilerek yatırım ataması gerçekleştirilir.

Adım 2: A sınıfinda bulunan toplam otobüs ya da durak sayısının toplam yatırım adedinden küçük ya da eşit olması durumunda küme içerisinde tüm elemanlara yatırımın uygulanması kararı alınır.

Adım 3: Kalan toplam yatırım adedi, B sınıfı eleman sayısından küçük ise küme içerisindeki elemanların niteliklere göre ağırlık değerleri hesaplanır ve ağırlık değeri yüksek olan hat numaralarına ya da duraklara öncelik verilerek yatırım ataması gerçekleştirilir.

Adım 4: Kalan toplam yatırım adedi B sınıfı eleman sayısından büyük ya da eşit ise B sınıfı elemanlarının tümüne yatırım uygulanması kararı alınır.

Adım 5: Kalan toplam yatırım adedi, C sınıfı eleman sayısından küçük ise küme içerisindeki elemanların niteliklere göre ağırlık değerleri hesaplanır ve ağırlık değeri yüksek olan hat numaralarına ya da duraklara öncelik verilerek yatırım ataması gerçekleştirilir.

Adım 6: Kalan toplam yatırım adedi $\mathrm{C}$ sınıfı eleman sayısından büyük ya da eşit ise $\mathrm{C}$ sınıfı elemanlarının tümüne yatırım uygulanması kararı alınır.

\section{Araştırma Sonuçları ve Tartışma}

\subsection{Araştırma Sonuçları}

Model 1, Model 2 ve Model 3 için yatırım atamasının yapıldığı A-B-C sinıflarındaki nesne sayısı Tablo 14'te görülmektedir.

\section{Tablo 14. A-B-C siniflarina ait nesne adetleri}

\begin{tabular}{l|c|c|c}
\hline \multirow{3}{*}{ Sınıf } & $\begin{array}{c}\text { Dış } \\
\text { Hoparlör } \\
\text { Sistemi } \\
\text { Yatırım } \\
\text { Adedi } \\
\text { (Model 1) }\end{array}$ & $\begin{array}{c}\text { Otobüs İçi } \\
\text { Akıllı } \\
\text { Bilgilendirme } \\
\text { Ekranı Yatırım } \\
\text { Adedi } \\
\text { (Model 2) }\end{array}$ & $\begin{array}{c}\text { Durak İçi } \\
\text { Akıllı } \\
\text { Bilgilendirme } \\
\text { Ekranı } \\
\text { Yatırım Adedi } \\
\text { (Model 3) }\end{array}$ \\
\hline$A$ & 100 & 685 & 32 \\
\hline$B$ & 0 & 215 & 301 \\
\hline$C$ & 0 & 0 & 167 \\
\hline
\end{tabular}

Yatırım adetlerinin A-B-C sınıfları arasındaki dağılımı Şekil 5 'te görülmektedir.

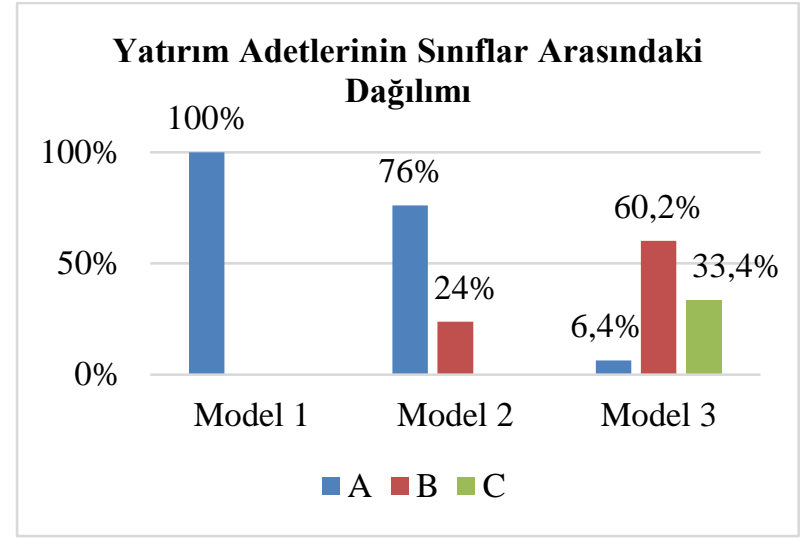

Şekil 5. Yatırım adetlerinin dăğlımı

Şekil 6'da, tüm engelli bireylerin en s1k kullandığı \%20'lik dilimde yer alan otobüs hattı numaraları ve diğer otobüs hatlarına olan talebe kıyasla kullanım oranları sıkıştırılmış olarak yer almaktadır. Çalışmanın sonucunda yatırım yapılmasına karar verilen otobüs hatları aşağıdaki grafikte mavi renk ile gösterilmişken, \%20'lik dilimde olmasına rağmen yatırım planına alınmayan otobüs hatları kırmızı renk ile gösterilmiştir.

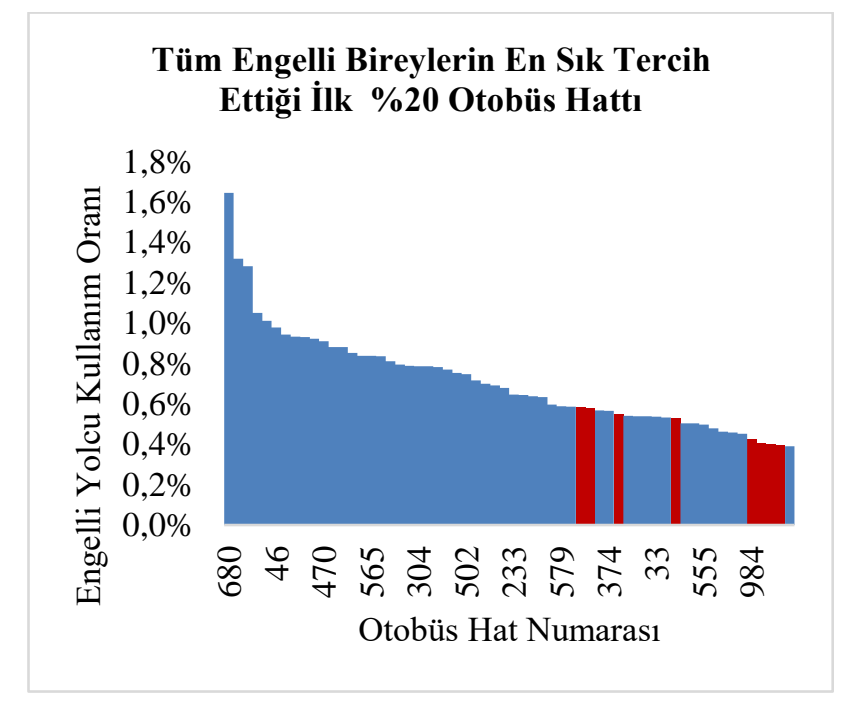

Şekil 6. Otobüs hattı talep grafiği

\subsection{Tartışma}

Çalışmadan elde edilen bulgulara göre; Model 1 ve Model 2'de yatırımın yapılmasına karar verilen otobüs hatları, toplu taşıma otobüsleri arasında tüm engellilerin en sık kullandığı \%20'lik dilimin içerisinde yer almaktadır. Model 3'te ise İzmir ilindeki 500 adet durağa yani tüm durakların \%7'sine yatırım yapılması planlanmıştır. Çalışmanın sonucundaki bulgulara göre yatırımın yapılması için belirlenen durakların \%85'i tüm engellilerin en sık kullandığ $1 \% 7^{\prime}$ lik dilimin içerisinde yer almaktadır. Belirtilen bu talep dilimlerinin dışında kalan diğer hat ve yatırım lokasyonları ise modellemede kullanılan ve seçimi önemli ölçüde etkileyebilecek farklı niteliklerin bulunmasından kaynaklanmaktadır. $\mathrm{Bu}$ bulgulara göre, çalışmada gerçekleştirilen veri madenciliği ve ABC sınıflandırma çalışmasının tutarlı sonuçlar verdiği sonucuna varılmaktadır.

Yatırım adetlerinin paylaştırılmasında ise bulgularda görüldüğü üzere A sınıfı elemanlarının \%100’ü yatırım planına alınmış, geri kalan adetler sırasıyla $\mathrm{B}$ ve $\mathrm{C}$ sınıflarına dağıtılmıştır. 
Bu çalışmada, standart sıralama yöntemleri yerine farklı bir bakış açısı kullanılarak, veri madenciliği yöntemi uygulanmış, seçim yapılması istenen nesnelerin benzer niteliklerine göre gruplandırılması yapılmış ve bu ABC sınıflandırmasının, söz konusu yatırım kararı dışında; gelecekteki diğer yatırım, planlama, bakım gibi çalışmalarda da rehber nitelikte olabilmesi sağlanmıştır.

Veri madenciliği konusunda yapılmış önceki çalışmalara kıyasla, bu çalışmada kamu kuruluşuna ait gerçek veriler kullanılmış, veri madenciliğinin yatırım kararlarında kullanılabilirliğgi gösterilmiş, yalın yöntemlerden olan $\mathrm{ABC}$ sınıflandırması ile nispeten yeni ve gelişmekte olan Endüstri 4.0 teknolojilerinden biri olan veri madenciliği yönteminin birbirini destekleyici olarak bir arada uygulanabilirliği gözler önüne serilmiştir. $\mathrm{Bu}$ çalışma; mühendislik uygulamalarının, kamu kurumlarında oldukça az sıklıkta kullanılıyor olması sebebiyle, diğer kamu kurum ve kuruluşlarına da öncülük ve rehberlik edebilecektir.

Yatırımların planlanan ilk kısmı uygulandıktan sonra ikinci kısım yatırımlar için model yeniden çalıştırılabilir. Yatırımların ilk kısım uygulamasının ardından engelli yolculardan geri bildirim alınarak modele yeni nitelikler eklenebilir ya da AHP önem dereceleri güncellenebilir.

Sonraki çalışmalarda modelleme için farklı veri madenciliği algoritmaları kullanılarak sonuçlar karşılaştırılabilir.

\section{Sonuçlar}

Bu çalışmada, şehir içi toplu taşıma hizmeti veren bir kamu kuruluşunun akıllı kartlardan elde ettiği büyük veri tabanı kullanılarak, engelli bireylerin yararına olması planlanan yatırımların hangi otobüs hattı ve hangi bölgelere yapılacağı kararı, veri madenciliği, AHP çok kriterli karar verme ve $A B C$ analizi yöntemleriyle desteklenmiştir. Veri madenciliği uygulaması ile hat ve duraklar kümelere ayrılmış, AHP yöntemi ile kümelerin birbirine göre üstünlük sıralaması yapılmış ve $\mathrm{ABC}$ analizi ile kümelerin nitelikleri belirlenerek yatırım dağılımı gerçekleştirilmiştir.

Model 1 ve Model 2 'de ABC analizinin temeli olan pareto ilkesine uygun bir sınıf dağılımı gerçekleşmiştir. K-means algoritma sonucuna göre; A sinıfı nesneler, tüm nesnelerin ilk $\% 20$ 'lik diliminde yer almaktadır. Model 3 'te ise nesne sayısı diğer modellere göre oldukça fazladır ve A sınıfında bulunan nesne sayısı \%0,4'lük dilimi kapsamaktadır. $\mathrm{Bu}$ oran pareto ilkesine uymamasına rağmen adetsel olarak kontrolü daha mümkün olduğu için çalışmaya faydalı bir sonuç olarak değerlendirilmiş ve farklı bir algoritma denenmesine gerek duyulmamıştır.

Çalışmanın sonucunda, kuruluş tarafindan planlanan toplam yatırım adetleri, oluşturulan algoritma doğrultusunda kümelerin içerisindeki nesnelere dağıtılarak detaylı yatırım planlaması desteklenmiştir. Genel tercih sıralamasındaki ilk \%20'lik dilim test verisi kabul edilerek modelin doğruluk kontrolü sağlanmıştır.

\section{Teşekkür}

$\mathrm{Bu}$ çalışmada kullanılan veriler, ESHOT Genel Müdürlüğü'nden temin edilmiştir.

\section{Kaynakça}

[1] Bekiroğlu, M. S. (2002). Peyzaj düzenlemelerinde özürlülerin kullanımları ile ilgili sorunların saptanması. Doktora Tezi, İstanbul Üniversitesi, Fen Bilimleri Enstitüsü, İstanbul.

[2] Lee, R. K. W., \& Kam, T. S. (2014). Time-series data mining in transportation: A case study on singapore public train commuter travel patterns. International Journal of Engineering and Technology, 6(5), 431-438.

[3] You, H., \& Yang, X. (2017). Urban expansion in 30 megacities of China: categorizing the driving force profiles to inform the urbanization policy. Land Use Policy, 68, 531-551.

[4] Zhang, N., Chen, H., Chen, X., \& Chen, J. (2016). Forecasting public transit use by crowdsensing and semantic trajectory mining: Case studies. ISPRS International Journal of Geo-Information, 5, 180-193.

[5] Zhuang, P., Shang, Y., \& Hua, B. (2009). Statistical methods to estimate vehicle count using traffic cameras, Multidimensional Systems and Signal Processing, 20(2), 121133.

[6] Y1lmazdamar, E. (2019). Toplu taşıma kullanan öğrencilerin hareketliliğinin analizi: Bursa örneği. Yüksek Lisans Tezi, Bursa Uludağ Üniversitesi, Sosyal Bilimler Enstitüsü, Bursa.

[7] Liu, D. R. \& Shih, Y. Y. (2005). Integrating AHP and data mining for product recommendation based on customer lifetime value. Information \& Management, 42(3), 387-400.

[8] Güçdemir, H., \& Selim, H. (2015). Integrating multicriteria decision making and clustering for business customer segmentation. Industrial Management \& Data Systems, 115(6), 1022-1040.

[9] Gemici, B. (2012). Veri madenciliği ve bir uygulaması. Doktora Tezi, Dokuz Eylül Üniversitesi, Sosyal Bilimler Enstitüsü, İzmir.

[10] Akpınar, H. (2000). Veri tabanlarında bilgi keşfi ve veri madenciliği. İstanbul Üniversitesi İşletme Fakültesi Dergisi, 29(1), 1-22.

[11] Evans, S., Lloyd, J., Stoddard, G., Nekeber, J., \& Samone, M. (2005). Risk factors for adverse drug events. The Annals of Pharmacotherapy, 39, 1161-1168.

[12] Dinçer, E. (2006). Veri madenciliğinde K-Means algoritması ve tıp alanında uygulanması. Yüksek Lisans Tezi, Kocaeli Üniversitesi, Fen Bilimleri Enstitüsü, Kocaeli.

[13] Kiyak, E., Timuş, O., \& Karayel, M. (2016). Inventory classification with ABC analysis. Journal of Naval Sciences and Engineering, 11(2), 11-24.

[14] Chen, J. X. (2012). Multiple criteria abc inventory classification using two virtual items, International Journal of Production Research, 50(6), 1702-1713.

[15] Gupta, M. K., \& Chandra, P. (2019). HYBCIM: Hypercube based cluster initialization method for k-means, International Journal of Innovative Technology Exploring Engineering, 8(10), 3584-3587.

[16] Gülenç, İ. F., \& Bilgin, G. A. (2010). Yatırım kararları için bir model önerisi: Ahp yöntemi, Öneri Dergisi, 9(34), 97 107.

[17] Özyörük, B., \& Özcan, E. C. (2008). Analitik hiyerarşi sürecinin tedarikçi seçiminde uygulanması: Otomotiv sektöründen bir örnek, Süleyman Demirel Üniversitesi İktisadi ve İdari Bilimler Fakültesi Dergisi, 13(1), 133-144.

[18] Saaty, T. L. (2008). Decision making with the analytic hierarchy process, International. Journal of Services Sciences, 1(1), 83-98. 